\section{Essentials of Orthodontics}

\section{Publisher: Jaypee Brothers Medical Publishers (P) Ltd}

Language: English

ISBN: 978-93-5090-329-2

Edition: $1 / \mathrm{e}$

Publish Year: 2013

Pages: 573, illustrated

Price: $£ 36.00$

The Essentials of Orthodontics by Aravind Sivaraj is a clear and a comprehensive guide to clinical and surgical orthodontics useful for dental students, postgraduate students and general practitioners.

The textbook is divided in 15 chapters. In the first three chapters the author talks about to the history and scope of orthodontics, the type of growth and development of dentition and occlusion, and different circumstances that may require orthodontic treatment. The following chapters discuss diagnosis and treatment planning, the mechanics of tooth movements, the preventive and interceptive orthodontics, as well as removable and fixed appliances, orthopedic and functional appliances, and retention and relapse.

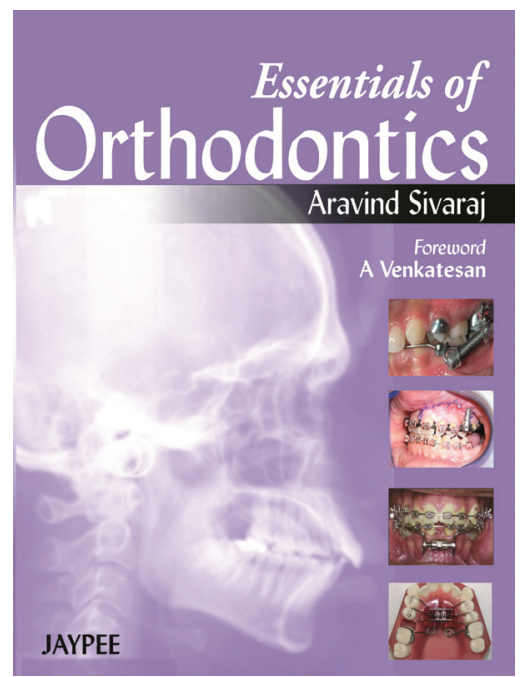

The other chapters describe surgical orthodontics from minor surgical procedures to orthodontic surgery and distraction osteogenesis, multidisciplinary orthodontics and medicolegal considerations. The last chapter presents and suggestively illustrates the instruments and materials used in orthodontics. The book achieves its purpose as a support for the theory and practice of current orthodontics.

https://doi.org/10.25241/stomaeduj.2016.3(1-2).bookreview.3

Marian-Vladimir Constantinescu,DDS, PhD

ROPOSTURO - Holistic Dental Medicine Institute, Bucharest, Romania

e-mail: dr.vladimir.constantinescu@gmail.com

The Book Review is drafted in the reviwer's sole wording and illustrates his opinions. 